\title{
Research on Post Fire Detection and Evaluation of Liu Jiang the Yellow River Bridge
}

\author{
Zeng Yong ${ }^{1 *}$, Ji Meng-Long ${ }^{2}$, Huang Shan-Feng ${ }^{3}$ \\ ${ }^{1}$ Bridge engineering, Bridge inspection and reinforcement, Zhengzhou, China \\ ${ }^{2}$ Bridge engineering, Disease Treatment and Prevention of Super Large Bridge on Expressway, Xinxiang, China \\ ${ }^{3}$ Bridge engineering, Disease Treatment and Prevention of Bridge, Luoyang, China
}

\begin{abstract}
After the bridge is damaged by fire, it is necessary to quickly probe the situation of the damaged structure, to take a response as soon as possible to ensure the safe passage of the bridge. A series of related work such as the component surface damage detection, carbonation depth, concrete strength testing and Axial compressive strength tested by core drilling combined with the analysis and calculation after fire had provided a basis for the safety assessment of structures. According to the results of the test and the conclusion of the finite element calculation, it was found that the bridge belongs to the dangerous situation, and the relevant strengthening measures should be taken.
\end{abstract}

\section{Prefaces}

With the development of the economy and the rise of logistics, the number of traffic and transportation is massive and the hidden dangers of bridge fire are also increasing. In recent years, reports on bridge fire incidents have been heard, and post disaster structural damage assessment and rapid reinforcement have also become new tasks for bridge operation and maintenance units. However, there are still few research data on the assessment of bridge fire and there are no relevant rules to follow. Therefore, the problems to be solved at the moment is to understand the damage mechanism of fire to bridges, to combine existing detection methods to detect and evaluate the degree of bridge damage after fire and to provide technical reference for bridge maintenance and reinforcement. At the same time, it is also a reference for similar bridge detection and evaluation.

\section{Engineering survey}

Liu Jiang the Yellow River highway bridge is located at the junction of Zhengzhou and Xinxiang, which is the throat engineering of the Beijing Hongkong and Macao Expressway across the Yellow River. At about 21:50 in February 28, 2016, two trucks followed as the vehicle carrying magnesium aluminum powder caught fire. Eventually the fire burned for nearly 27 hours on the deck. The location of the fire accident is the eleventh span of the Approach bridge Downline, that is to say the spot is $\mathrm{K} 642+150$. The superstructure is $35 \mathrm{~m}$ span prestressed concrete simply supported $\mathrm{T}$ beam with $2.3 \mathrm{~m}$ center height and the width of the single lane is $19 \mathrm{~m}$.

\section{Detection and evaluation scheme and content}

In order to quickly detect the current status of the bridge so as to judge the possibility to pass or to be restricted. The following plan is formulated. The components of the fire site are divided into three parts: the concrete damage area (the area of concrete falling or cracking due to the fire components), the affected area (the components obviously smoked) and the last is the unaffected area. In order to save time, we usually carry out routine tests first. If necessary, we need to do comparative tests or sample analysis for different areas so as to determine and draw feasible conclusions and provide basis for subsequent reinforcement.

The bridge detection mainly includes the following contents: 1) structural historical investigation; 2) fire investigation; 3) component surface damage and appearance detection; 4) component carbonation depth detection; 5) component concrete strength detection; 6) component core drilling detection.

\section{Detection methods and conclusions}

\subsection{Appearance detection}

Firstly, the beam component by the fire burning damage were detected and we analysed cracks and crack factors to ascertain the nature of the canvass beam. The following $10 \#$ pier substructure fire area and influence degree were checked including the crack and Dew phenomenon. It cannot be ignored about bearing burned deformation. At last detection of damaged facilities such

\footnotetext{
$\overline{{ }^{*} \text { Corresponding author: 805647220@qq.com }}$
} 
as pavement, expansion joints, vent pipes, railings were performed and a series of problems about the blackened area, broken, pits, longitudinal or transverse crack area, length and position were simultaneously recorded.

There were two burned areas located in the West tenth span and eleventh span. The main disease included: deformation and softening of deck asphalt pavement, local concrete pavement loose and broken and exposed rebar, concrete $\mathrm{T}$ girder flange forming hollow. Another disease about part of burned asphalt pavement areas was the secondary injury at the cleaning process because the burring fallen at the deck. The Anti-glare panel near the middle span was heated. Fortunately, the bridge supports have not found the obvious disease.

\subsection{Component deformation detection}

The longitudinal linear was measured between the eleventh span and the twelfth span. Along the 3 lines (bridge axis, up- edge and down- edge), longitudinal direction of the bridge is divided into 5 sections to measure.

The closed levelling measurement was executed according to two engineering levelling requirements. As shown in Figure 1, measuring points arrangement, test results are shown in table 1.

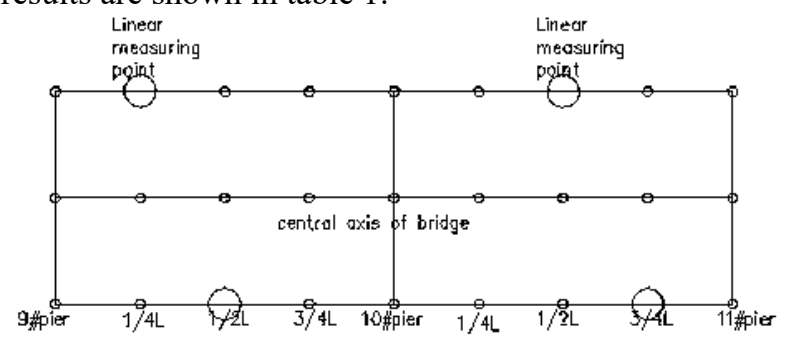

Fig. 1. Layout map of bridge alignment point.

Table 1. Test results of bridge alignment.

\begin{tabular}{|c|c|c|c|}
\hline \multirow{2}{*}{$\begin{array}{l}\text { Longitudinal } \\
\text { location } \\
\quad(\mathrm{m})\end{array}$} & \multicolumn{3}{|c|}{ relative elevation $(\mathrm{m})$} \\
\hline & $\begin{array}{c}\text { upstream- } \\
\text { edge }\end{array}$ & $\begin{array}{l}\text { bridge } \\
\text { axis }\end{array}$ & $\begin{array}{l}\text { downstre } \\
\text { am- edge }\end{array}$ \\
\hline $9 \# p$ & -1.737 & -1.557 & -1.363 \\
\hline $1 / 4 \mathrm{~L}$ & -1.7 & -1.558 & -1 . \\
\hline $1 / 2 \mathrm{~L}$ & -1.7 & -1.539 & 66 \\
\hline $3 / 4 \mathrm{~L}$ & -1.7 & -1.539 & \\
\hline $10 \# \mathrm{pi}$ & -1.7 & -1.6 & -1 . \\
\hline $1 / 4 \mathrm{~L}$ & -1.724 & -1.688 & -1.363 \\
\hline $1 / 2 \mathrm{~L}$ & -1.723 & -1.675 & -1.361 \\
\hline $3 / 4 \mathrm{~L}$ & -1.719 & -1.541 & -1.365 \\
\hline 11\#pier & -1.727 & -1.542 & -1.377 \\
\hline
\end{tabular}

It can be seen from table 1 that the elevation distribution was basically straight line along the upstream- edge and downstream- edge but the middle axle position appeared a concave state which was due to the measured points located in the chiselled deck. In a cross section, the three points measured still maintained a straight which basically coincided with the bridge cross slope. The results show that the bridge stiffness was basically not affected after the fire.

\subsection{Carbonization depth detection}

The depth of concrete carbonation was tested by the alcohol phenolphthalein solution. At first, test area surface was drilled $15 \mathrm{~mm}$. It's worth noting that the drilled depth must bigger than the carbonization depth and alcohol Phenolphthalein solution was with concentration of $1 \%$. Then the prepare solution were droplet in the inner wall of the cavity edge. When the boundaries of the carbonization or not was clear, we can measure the vertical distance from the surface of the concrete to the colour changed boundary. The measurement is not less than 3 times. At last, the average vale was regarded as carbonization depth of the area.

The depth of concrete carbonation is tested on 3 areas including the damage area, the affected area and the unaffected area of each $\mathrm{T}$ beam from the 11th span1 8\#T beam. According to the test results of concrete carbonation depth, the carbonation depth of the undamaged part was $0.5-1.0 \mathrm{~mm}$, the carbonization depth of the top side of the $6 \#$ beam was $1.5-2.0 \mathrm{~mm}$, and the carbonization depth of the top side of the east side of the $5 \#$ beam was the most seriously affected by fire.

According to the "bearing capacity of highway bridge detection and evaluation procedures (JTG/T J212011)", the result showed the concrete damaged fire was 1 degree, so as to correctly judge the influence of concrete carbonation depth on the steel corrosion.

\subsection{Test about Rebound strength of concrete}

Although the rebound method is not suitable for concrete structure test with the surface and internal different quality and it is not suitable for the detection of concrete after fire, you can learn from the principle of the method that the surface hardness of concrete suffered fire is able to reflect the extent of the fire damage. In fact, the strength test of the concrete component can be carried out by the rebound method and the core drilling method. The rebound strength method is used to detect the concrete strength in the concrete stripping area, the affected area and the unaffected area, and to predict the quality deterioration area caused by the fire.

The following problem during the rebound value measurement were important. Generally, the measure points evenly distributed in the test area and the spacing of the adjacent sides was no less than $20 \mathrm{~mm}$. The distance between the measured point and exposed steel bars was no less than $30 \mathrm{~mm}$. It's worth noting that the measuring points should not be in the pores or exposed stones. The same measuring point should only be struck one time and the 16 rebound value were got from each test area. After the rebound test was completed, the carbonization depth should be measured at the representative position of the measuring points. The average value was the carbonization depth of each component area and the strength of concrete would be 
investigated according to the average number of springback and the depth of carbonation. The results of the test date were shown in the table 2 . In the table $2, \mathrm{~A}$ means the distance away from the root of $\mathrm{T}$ wing plate, $\mathrm{B}$ means the rebound strength of the test area and $\mathrm{C}$ means the carbonation dept. The unit of all those parameters directly displayed at the table 2 .

The rebound value is tested on 10 areas including the damage area, the affected area and the unaffected area of each $\mathrm{T}$ beam from the 11 th span $1 \sim 8 \# \mathrm{~T}$ beam. All measurement areas were 240 .

Table 2. Rebound primary data of the bridge.

\begin{tabular}{|c|c|c|c|c|}
\hline Component & location & $\mathrm{A}(\mathrm{cm})$ & $\mathrm{B}(\mathrm{MPa})$ & C (mm) \\
\hline \multirow{4}{*}{$\begin{array}{l}\text { 5\#beam } \\
\text { east web }\end{array}$} & \multirow{4}{*}{$\begin{array}{l}\text { 3\#diaphra } \\
\text { gm north }\end{array}$} & $\begin{array}{l}0 \\
\end{array}$ & 51.1 & 3 \\
\hline & & 15 & 56.4 & 2 \\
\hline & & 30 & 54.6 & 1.5 \\
\hline & & 45 & $>60$ & 0.5 \\
\hline \multirow{6}{*}{$\begin{array}{l}\text { 5\#beam } \\
\text { east web }\end{array}$} & \multirow{6}{*}{$\begin{array}{l}\text { 3\#diaphra } \\
\text { gm south }\end{array}$} & 0 & 46 & 3 \\
\hline & & 15 & 51 & 2.5 \\
\hline & & 30 & 54.5 & 2 \\
\hline & & 45 & 59.65 & 1 \\
\hline & & 60 & $>60$ & 0.5 \\
\hline & & 75 & 58.9 & 1 \\
\hline \multirow{4}{*}{$\begin{array}{l}\text { 5\#beam } \\
\text { west web }\end{array}$} & \multirow{4}{*}{$\begin{array}{l}\text { 3\#diaphra } \\
\text { gm north }\end{array}$} & 0 & 56.3 & 2.5 \\
\hline & & 15 & 53.6 & 2 \\
\hline & & 30 & $>60$ & 1 \\
\hline & & 45 & $>60$ & 0.5 \\
\hline \multirow{4}{*}{$\begin{array}{l}5 \# \text { beam } \\
\text { west web }\end{array}$} & \multirow{4}{*}{$\begin{array}{l}\text { 3\#diaphra } \\
\text { gm south }\end{array}$} & 0 & 49.8 & 2 \\
\hline & & 15 & $>60$ & 1 \\
\hline & & 30 & $>60$ & 1 \\
\hline & & 45 & $>60$ & 0.5 \\
\hline \multirow{4}{*}{$\begin{array}{l}5 \# \text { beam } \\
\text { east web }\end{array}$} & \multirow{4}{*}{$\begin{array}{l}\text { 6\#diaphra } \\
\text { gm south }\end{array}$} & 0 & $>60$ & 1.5 \\
\hline & & 15 & $>60$ & 1 \\
\hline & & 30 & $>60$ & 1 \\
\hline & & 45 & $>60$ & 1 \\
\hline \multirow{4}{*}{$\begin{array}{l}\text { 6\#beam } \\
\text { west web }\end{array}$} & \multirow{4}{*}{$\begin{array}{l}\text { 2\#diaphra } \\
\text { gm south }\end{array}$} & 0 & 49.2 & 2 \\
\hline & & 15 & 57.6 & 1.5 \\
\hline & & 30 & $>60$ & 1 \\
\hline & & 45 & $>60$ & 1 \\
\hline \multirow{4}{*}{$\begin{array}{l}\text { 6\#beam } \\
\text { west web }\end{array}$} & \multirow{4}{*}{$\begin{array}{l}\text { 3\#diaphra } \\
\text { gm north }\end{array}$} & 0 & 52.3 & 2 \\
\hline & & 15 & $>60$ & 1 \\
\hline & & 30 & $>60$ & 1 \\
\hline & & 45 & $>60$ & 1 \\
\hline \multirow{4}{*}{$\begin{array}{l}\text { 6\#beam } \\
\text { west web }\end{array}$} & \multirow{4}{*}{$\begin{array}{l}\text { 3\#diaphra } \\
\text { gm south }\end{array}$} & 0 & 51.3 & 2 \\
\hline & & 15 & 51.1 & 2 \\
\hline & & 30 & $>60$ & 0.5 \\
\hline & & 45 & $>60$ & 0.5 \\
\hline \multirow{4}{*}{$\begin{array}{l}\text { 6\#beam } \\
\text { east web }\end{array}$} & \multirow{4}{*}{$\begin{array}{l}\text { 3\#diaphra } \\
\text { gm south } \\
3 m\end{array}$} & 0 & $>60$ & 1 \\
\hline & & 15 & $>60$ & 1.5 \\
\hline & & 30 & $>60$ & 0.5 \\
\hline & & 45 & $>60$ & 0.5 \\
\hline \multirow{4}{*}{$\begin{array}{c}6 \# \text { beam } \\
\text { west web }\end{array}$} & \multirow{4}{*}{$\begin{array}{l}\text { 6\#diaphra } \\
\text { gm north }\end{array}$} & 0 & 56.8 & 1 \\
\hline & & 15 & $>60$ & 1 \\
\hline & & 30 & $>60$ & 1 \\
\hline & & 45 & $>60$ & 0.5 \\
\hline \multirow{4}{*}{$\begin{array}{c}\text { 7\#beam } \\
\text { west web }\end{array}$} & \multirow{4}{*}{$\begin{array}{l}\text { 3\#diaphra } \\
\text { gm south } \\
3 m\end{array}$} & 0 & $>60$ & 0.5 \\
\hline & & 15 & $>60$ & 0.5 \\
\hline & & 30 & $>60$ & 0.5 \\
\hline & & 45 & $>60$ & 0.5 \\
\hline
\end{tabular}

The test results showed that the rebound strength of concrete surface in undamaged area was greater than $60 \mathrm{MPa}$, and the rebound strength of concrete surface in damaged area is within $46-50 \mathrm{MPa}$ range.

\subsection{Detection about core drilling method}

According to "The Technical Specification for Concrete Strength Detection by Core Drilling Method", the strength of concrete is tested by small core sampling method. Core location is selected in the concrete damaged area, the unaffected area, and the strength results were mutual verified with the rebound method.

Twenty-four effective concrete core samples were taken, and the cracks were found on the surface of the concrete core. Because of the limited space, the compressive strength of concrete core is not listed, its test results show that the compressive strength of concrete core was $50.60-64.93 \mathrm{MPa}$ from the less affected areas, and the compressive strength of concrete was $8.16-62.49 \mathrm{MPa}$ from the burned areas. All those showed that the fire had obvious impact on the strength of concrete and the residual strength cannot meet with the requirement of the original design.

\subsection{Steel drawing contrast test}

After sampling of the steel bar site, the tensile strength contrast test was executed between the subjected by fire and not. Test resulted show that the unfired steel yield strength and ultimate tensile strength were $290 \mathrm{MPa}$ and $410 \mathrm{MPa}$; on the contrary the strength fired were $177 \mathrm{MPa}$ and $330 \mathrm{MPa}$. It can be concluded that tensile strength had serious loss by the fire.

\section{Conclusions}

Detection and evaluation of bridges after fire is an important issue faced by bridge maintenance units. Effectively reflecting the state of fire damage will be a strong evidence for further reinforcement. Based on a case study, a series of relevant on-site indicators and indoor tests and computer calculation provide an important basis for the structural grade evaluation of the bridge, and, of course, provide a useful reference for similar concrete bridges after fire detection and reinforcement.

At present, there is still less research data on bridge fire detection and evaluation, and some methods have some limitations for bridge evaluation after fire. Although at this stage of testing the strength of concrete core sampling method is the most accurate and direct method for detecting, there are still some deviations. Of course, it will be in favor with the general public that we find some affordable refractory type pavement material which can avoid the occurrence of fire or improve the ignition point to reduce fire occurrence probability. 


\section{References}

1. CAI Zheng-dong; PENG Xu-min; HUANG Qing. Inspection and Assessment of Concrete Girder Bridge Damaged by Fire[J]. World Bridges, 6, P7478 (2014)

2. Huang Qing. Inspection and Evaluation of Reinforced Concrete Bridges after Fire Disasters. World Bridges, 5, P78-82 (2014)

3. Li Yi; XIANG Yi-qiang; WANG Jiang-jiang. Damage Inspection and Security Assessment for Bridge after Fire. China municipal engineering, 5, P26-27 (2006)

4. HE Fo-sheng XU Zhao-feng. Detection and Assessment on Reinforced Concrete Bridge After the fire. GuangDong Highway Communications, 2, P30-33(2009)

5. FENG Zhao-Xiang; XIAN-Yue; MIU Chang-Qing. Test and Assessment of Prestressed Concrete Bridge after Fire. 5, P230-236 (2015)

6. MA Hu. Fire Damage Identification and Valuation of Box Beam of Continuous Rigid Frame Bridge. Chongqing Architecture, 9, P38-40 (2015)

7. LIU Hua; GAO Zong-Yu; LIU Qi-Wei; ZHANG Jun-lei. Assessment and Strengthening of a Fire Damaged Prestressed Concrete Continuous. Bridge Construction, 4, P81-87 (2015) 